\title{
NIILISMO E RESSENTIMENTO NA TERCEIRA DISSERTAÇÃO DA GENEALOGIA DA MORAL
}

NIHILISM AND RESENTMENT IN THE THIRD DISSERTATION OF OF MORAL

\author{
ANTONIO EDMILSON PASCHOAL ${ }^{1}$ \\ Universidade Federal do Paraná (UFPR) - Brasil \\ antonio.paschoal@yahoo.com.br
}

\begin{abstract}
RESUMO: No prefácio da Genealogia da moral, Nietzsche anuncia que a terceira dissertação daquele livro consiste na interpretação de um aforismo. O aforismo em questão diz respeito ao perigo que representa para o homem a falta de sentido para o sofrimento e também às soluções adotadas no Ocidente para enfrentar esse perigo. De fato, a formulação daquele aforismo corresponde a um desdobramento da seção final de $O$ mundo como vontade e representação, de Schopenhauer. Assim, a compreensão da interpretação que se segue ao aforismo deve considerar esse vínculo entre a terceira dissertação da Genealogia da moral e o livro de Schopenhauer, o modo como Schopenhauer sintetiza as principais soluções para aquele problema e também a crítica de Nietzsche a Schopenhauer. Uma crítica construída em grande parte, conforme pretendo mostrar, sobre o conceito de ressentimento.
\end{abstract}

PALAVRAS-CHAVE: Niilismo. Ressentimento. Ascese. Ideal Ascético. Schopenhauer. Dühring.

ABSTRACT: In the preface of Genealogy of Morals, Nietzsche announces that in the book's third dissertation the interpretation of an aphorism would be offered. The aphorism in question pertain to the danger imposed by the meaninglessness of the suffering and to the solutions adopted by the West to address this danger. As is well known, the formulation of that corresponds to an unfolding of the final section of Schopenhauer's The World as Will and Representation. Thus, the understanding of the interpretation that follows the aphorism formulation must consider this link between the third dissertation of Genealogy of Moral and the book of Schopenhauer, must take into account the way that Schopenhauer synthesizes the problem's main solutions, and also criticism of Nietzsche to Schopenhauer. A critique built largely, as we intend to show, from the concept of resentment.

KEYWORDS: Nihilism. Resentment. Asceticism. Ascetic Ideal. Schopenhauer. Dühring.

\section{CONSIDERAÇÕES INICIAIS}

A terceira dissertação da Genealogia da moral é, ao certo, um dos textos publicados de Nietzsche no qual se tem um maior desenvolvimento do tema do niilismo. Como é conhecido, Nietzsche abre esse texto justamente com o problema da vontade de nada, num claro vínculo com a filosofia de Schopenhauer, e o

\footnotetext{
${ }^{1}$ Professor do Programa de Pós-Graduação em Filosofia da Universidade Federal do Paraná (UFPR) e pesquisador do CNPq. O presente trabalho foi realizado com apoio da Coordenação de Aperfeiçoamento de Pessoal de Nível Superior - Brasil (Capes) - Código de Financiamento 001.
} 
desdobra com uma série de perguntas acerca do significado do ideal ascético, com destaque para a figura do sacerdote ascético e para os meios utilizados por ele para impedir que o sofredor chegue a um patamar de sofrimento que seria, nas palavras de Nietzsche, um "niilismo suicida" (GM III 28)². É esse desdobramento que pretendo retomar neste artigo, com o objetivo de mostrar, por um lado, o uso estratégico dos afetos do ressentimento, feito pelo sacerdote ascético e, por outro, o modo como Nietzsche mobiliza o conceito de ressentimento para a sua crítica ao sacerdote ascético e, pari passo, à filosofia de Schopenhauer.

O aforismo que é o objeto de interpretação na terceira dissertação da Genealogia da moral, que sintetiza uma das questões mais enigmáticas da filosofia de Nietzsche, é formulado por ele nos seguintes termos: "no fato de o ideal ascético haver significado tanto para o homem, porém, se expressa o dado fundamental da vontade humana, o seu horror ao vácuo [horror vacui]: ele precisa de um objetivo e preferirá ainda querer o nada a nada querer" (GM III 1).

A interpretação desse enigmático aforismo recebe contornos abrangentes no início da dissertação, quando são elencados os significados do ideal ascético para diversos grupos de pessoas e também diferentes concepções de ideais ascéticos, além de alguns modos como a ascese pode se manifestar, ligada ou não a um ideal. É nesse sentido, ainda muito abrangente, que Nietzsche se pergunta pelo significado do ideal ascético, por exemplo, para os artistas, para as mulheres e para os filósofos. Esse último grupo, aliás, o dos filósofos, recebe um tratamento especial no texto, permitindo espelhar uma acepção de ascese entendida como um meio, como um exercício, sem ser vinculada necessariamente a um ideal. Nesse momento, quando Nietzsche claramente se inclui no grupo investigado, ele afirma que "um certo ascetismo" faz parte do ofício do filósofo. Assim, numa passagem que parece contemplar suas próprias condições de trabalho, ele postula que o ideal ascético, entendido como “(...) uma dura e serena renúncia feita com a melhor vontade, está entre as condições propícias à mais elevada espiritualidade, e também entre as suas consequências mais naturais" (GM III 9).

Seguindo o texto, o comentário passa pela figura do homem contemplativo e pela associação entre o filósofo e o sacerdote, com quem se estabelece um vínculo inquebrantável da ascese com um ideal no além, que coloca a ascese em movimento. A partir de então, o ideal ascético não será mais considerado no plural, mas no singular. Isto porque, segundo Nietzsche, é nesse ponto, quando

\footnotetext{
${ }^{2}$ As citações de Nietzsche serão feitas seguindo um padrão já estabelecido em siglas. Assim, na citação em tela, a sigla GM corresponde ao livro Para a genealogia da moral, o número em algarismo romano III, à parte do livro e o número em algarismo arábico 28 à seção no interior daquela parte. Outras siglas utilizadas serão A, que corresponde a Aurora, seguida, no caso, do número do aforismo; AC, que corresponde a O Anticristo, seguida igualmente pelo número do aforismo; $\mathrm{EH}$, que corresponde a Ecce homo, no caso, seguido pelo título da parte do livro e do número da seção. Para as citações de anotações pessoais de Nietzsche será indicada a sigla KSA (de Kritische Studienausgabe), seguida do número do volume e da página em que a passagem se encontra. Será utilizada ainda a sigla MVR para a obra $O$ mundo como vontade e representação de Arthur Schopenhauer, seguida do número da seção da obra em que a passagem se encontra. As demais citações serão feitas por meio do sistema autor, ano e página, com a referência completa ao final do artigo, onde se encontram também as referências completas das obras utilizadas de Nietzsche e de Schopenhauer.
} 
"avistamos o sacerdote ascético", que "atacamos seriamente nosso problema: o que significa o ideal ascético?" (GM III 11).

\section{PRIMEIRAS CONFLUÊNCIAS ENIRE NIILISMO E RESSENTIMENTO}

O sacerdote ascético é uma figura ad hoc, delineada por Nietzsche especialmente para a terceira dissertação da Genealogia da moral. Ele não se compara, por exemplo, com as outras figuras que aparecem na dissertação, como é o caso dos artistas e dos filósofos, para os quais o ideal ascético poderia ter diversos significados e, ocasionalmente, um significado transmundano. Diferentemente deles, o sacerdote ascético sequer poderia ser pensado sem aquela perspectiva de um além mundo. Nas palavras de Nietzsche, "não apenas a sua fé, mas também sua vontade, seu poder, seu interesse. Seu direito à existência se sustenta ou cai com esse ideal" (GM III 11).

Esse personagem peculiar apresenta também características próprias quando comparado com outros sacerdotes que aparecem nos escritos de Nietzsche, como é o caso, por exemplo, das aristocracias sacerdotais, delineadas por ele na primeira dissertação da Genealogia. De fato, assim como aquelas aristocracias, o sacerdote ascético apresenta hábitos hostis à vida, tais como "certas formas de dieta (abstinência de carne), o jejum, a continência sexual, a fuga para o deserto" e outras práticas de "auto-hipnose" (GM I 6). Contudo, diferentemente daquelas aristocracias sacerdotais, que aparecem no texto como um capítulo da história da emergência de uma determinada moral, o sacerdote ascético corresponde às estratégias utilizadas por essa moral para se tornar dominante. Em termos mais precisos, suas ações consistem em prescrever medicamentos para o seu rebanho, para que ele não se perca e, ao mesmo tempo, dispensar narcóticos para aqueles que poderiam ameaçar esse rebanho. Suas ações corresponderiam, em resumo, aos meios utilizados para a manutenção do homem fraco na existência e também ao modo como esse tipo de homem se converte em uma meta para toda a humanidade, num grande projeto de "apequenamento do tipo homem" (GM I 12).

Segundo Nietzsche, as estratégias utilizadas pelo sacerdote ascético são claramente avessas ao "autêntico instinto de vida" (GM III 12). Elas são hostis a qualquer forma de vida transbordante, a tudo o que na vida é exuberância, vontade, afetos etc. Contudo, paradoxalmente, essas estratégias se mostram de tal modo impregnadas na vida e na cultura que Nietzsche se vê obrigado a perguntar se a concretização delas não corresponderia a um "interesse da vida mesma" (GM III 11). Ou seja, se em todo aquele empenho de uma vida que se volta contra si mesma não haveria "um artificio para a preservação da vida" (GM III 13). De fato, a resposta de Nietzsche a essa pergunta é afirmativa. Para ele aquelas estratégias do sacerdote devem expressar uma tática de preservação da vida, porém, de uma forma de vida em particular, na qual se evidenciaria a condição doentia do homem. Elas corresponderiam, assim, a um "instinto de cura e proteção de uma vida que degenera" (GM III 13). 
O ponto de inflexão da dissertação é, portanto, o perigo que representa para o homem as respostas ao seu maior desafio. O desafio que consiste em conferir um sentido ao sofrimento que é inerente à existência e que ganha contornos peculiares em situações de fraqueza. Nesse contexto, como se pode observar, o niilismo pode ser tanto a expressão para aquela possibilidade de suicídio que se encontra no extremo do horror vacui, quanto o nada proposto pelo sacerdote ascético como solução para o problema do sofrimento. É especialmente para esse segundo niilismo que Nietzsche volta sua atenção na sequência do texto.

Acompanhando Schopenhauer, Nietzsche associa aquela vontade de nada ao cristianismo e às demais religiões que, de algum modo, oferecem como solução para o sofrimento do homem uma expectativa em uma vida no além, no nada. ${ }^{3} \mathrm{~A}$ saída sacerdotal se configura, assim, nas palavras de Nietzsche, a um "afastamento niilista da vida, [ao] anseio do nada" (GM II 21). A efetivação dessa meta, contudo, passa pelo modo como o sacerdote relaciona esse niilismo ao ressentimento. Em especial pelo modo como ele fará a ligação entre a "grande compaixão pelo homem" (GM III 14) e aquele ideal transmundano como uma alternativa para o perigo que representa o horror vacui.

A compreensão dessa confluência entre esse niilismo e o ressentimento passa, assim, por um olhar atendo a um dos principais subterfúgios adotado pelo sacerdote que é a reinterpretação do sofrimento do homem, como culpa e pecado. Nesse sentido, como um hábil estrategista, ele toma a sede de vingança do sofredor, que procura por um culpado para o seu sofrimento, por um "inimigo mau" (GM I 10), e a direciona para o interior daquele homem que sofre. Nas palavras de Nietzsche:

"Eu sofro: disso alguém deve ser culpado" - assim pensa toda ovelha doente. Mas seu pastor, o sacerdote ascético, lhe diz: "Isso mesmo, minha ovelha! Alguém deve ser culpado: mas você mesma é esse alguém - somente você é culpada de sil" Isto é ousado bastante, falso bastante: mas com isto se alcança uma coisa ao menos, com isto, como disse, a direção do ressentimento é mudada. (GM III 15).

\section{ASCESE E RESSENTIMENTO}

A acepção de ascese que aparece nessa passagem, relacionada ao ressentimento e que traduz em grande medida o significado da ideia de ascese que se tem nessa dissertação, remonta a uma ideia esboçada por Nietzsche 12 anos antes, em 1875, nas "conclusões próprias" que apresenta após a resenha que fez

\footnotetext{
${ }^{3}$ É interessante, nesse sentido, a leitura do artigo intitulado "Schopenhauer mestre de Nietzsche: sobre niilismo e ascetismo", de João Constâncio, publicado em 2018, na Revista Sofia (v. 7, n. 02, p. 59-81). Nesse artigo, Constâncio coloca em relevo o vínculo entre Nietzsche e Schopenhauer, em especial pela concepção de niilismo que se tem na terceira dissertação da Genealogia da moral, como um modo de querer o nada, que o filósofo teria retirado diretamente de Schopenhauer. De minha parte, reitero também o vínculo da terceira dissertação com o pensamento de Schopenhauer, contudo, considerando não apenas o niilismo, mas também o ressentimento, termino por colocar em relevo o diálogo entre ambos e, em especial o papel de Schopenhauer como um adversário de Nietzsche no texto.
} 
do livro de Eugen Dühring "O valor da vida” (KSA 8, p. 180). Ali, Nietzsche afirma que o conhecimento de si que se tem no cristianismo relaciona-se com um desprezo de si e, na ausência desse desprezo, a uma espécie de misericórdia para consigo - uma autopiedade. Nesse sentido, trabalhando ainda sob a influência de Dühring, Nietzsche conclui que aquele autoconhecimento cristão estaria ligado à ideia de vingança, na medida em que ele surge como uma investigação pautada numa "justiça contra si mesmo", sendo a ideia de justiça, no caso, compreendida como um "sentimento de vingança" (KSA 8, p. 180). Uma ideia que reaparece numa tese formulada por ele nos seguintes termos: "Se alguém já sofreu bastante, se já feriu bastante a si mesmo, por sua pecaminosidade - ele começa a experimentar contra si mesmo o sentimento de vingança: de sua penetrante observação de si resulta o autodesprezo. Em algumas pessoas isto é a própria ascese, isto é, a vingança direcionada para si mesmo em função da aversão e do ódio" (KSA 8, p. 180).

Nesse sentido, superar o cristianismo, seria sobrepujar esse vínculo do conhecimento de si com a aversão por si - e também com a compaixão por si mesmo. O que denota, considerando ainda os apontamentos feitos por Nietzsche naquele momento, uma diferença essencial entre o cristão e o budista, pois o budista não desenvolveria aquele tipo de olhar que se volta rancoroso contra si mesmo, uma vez que nele não se encontraria aquela ideia de pecaminosidade. Contudo, confrontando esses apontamentos e o modo como o budismo aparece na terceira dissertação da Genealogia, em especial na seção 17, é possível observar uma diferença essencial entre os dois textos, uma vez que naquela seção da Genealogia Nietzsche não distingue o budismo do cristianismo.

A compreensão dessa diferença, que diz respeito, em parte, ao modo multifacetado como o budismo aparece na filosofia de Nietzsche, ${ }^{4}$ deve considerar, a princípio, uma questão metodológica. Trata-se de uma fluidez de sentidos que o conceito apresenta, dependendo das interlocuções e das demandas especificas que se tem em cada contexto a cada vez que ele aparece. Desse modo, enquanto em 1875 Nietzsche considerava a ideia de pecaminosidade, na seção 17 da terceira dissertação da Genealogia da moral encontra-se em evidência a ideia de redenção. Além disso, o texto de 1887 é profundamente marcado pelo diálogo de Nietzsche com Schopenhauer, evidenciando-se, então, o modo como seu mestre, aborda o tema da negação da vontade, sem distinguir o cristianismo do budismo, uma vez que ambas seriam, sob o aspecto que interessa a ele, religiões niilistas. O que será considerado atentamente por Nietzsche que, pauta também a sua abordagem das religiões, nessa parte da Genealogia, justamente por aquela expectativa criada por elas em relação ao nada. Ou seja, a partir da ideia de redenção. Uma ideia que, nas palavras de Nietzsche, se expressa como a "quietude total enfim alcançada" (GM III 17) e pela libertação das cadeias, pela superação daquilo que se traduz pela expressão "bem e mal", isto é, as coisas deste mundo.

\footnotetext{
${ }^{4}$ As diferentes conotações que o budismo recebe na obra de Nietzsche foram analisadas de forma mais detalhada em: PASCHOAL. Do niilismo às artes de higiene: o budismo nos escritos de Nietzsche. In: André Luiz Muniz Garcia e Lucas Angioni (orgs.). Labirintos da Filosofia: Festschrift aos 60 anos de Oswaldo Giacoia Jr. Campinas: Editora Phi, 2016, pp. 234-252.
} 
De fato, sob esse aspecto, o da redenção, o budismo seria tão "moralizado" quanto as demais religiões (GM III 17). Isso, porém, não faz com que a ele seja possível associar a ideia de pecado, e nisso se mantém a sua diferença em relação ao cristianismo. Uma diferença que é colocada em relevo por Nietzsche mais adiante, na seção 27, quando aponta a ideia de uma origem ateia do budismo, ${ }^{5} \mathrm{e}$ que é retomada por ele com mais vigor um ano depois, em Ecce homo.

Em 1888, em sua autobiografia, Nietzsche diferencia as práticas ascéticas encontradas no budismo das praticas cristãs justamente pelo modo como ambas se posicionam em relação ao ressentimento. Enquanto no cristianismo ele tem um papel preponderante, como uma sede de vingança que se volta contra o próprio sofredor em função da ideia de pecado, no budismo a superação do ressentimento é uma pré-condição para se sair da condição de sofredor, de doente. Nas palavras de Nietzsche:

\begin{abstract}
Isso compreendeu aquele profundo fisiólogo que foi Buda. Sua 'religião', que se poderia designar mais corretamente como uma higiene, para não confundi-la com coisas lastimáveis como o cristianismo, fazia depender sua eficácia da vitória sobre o ressentimento: libertar a alma dele - primeiro passo para a convalescença. 'Não pela inimizade termina a inimizade, pela amizade termina a inimizade'; isso se acha no começo dos ensinamentos de Buda - assim não fala a moral, assim fala a fisiologia. (EH I 6).
\end{abstract}

\title{
4 O RESSENTIMENTO COMO MEDIDA PARA A FALTA DE MEDIDA
}

Nesses dois modos de se correlacionar com a vingança seria possível, assim, demarcar algumas peculiaridades das duas religiões enquanto modos de solucionar o problema do sentido do sofrimento. Enquanto expectativas futuras que levam à negação deste mundo ambos, o budismo e o cristianismo, atuam moralmente. $O$ cristianismo, por sua esperança em um além, o budismo, por sua expectativa pelo Nirvana (MVR 71), pelo eterno "sem sentido" (KSA 12, p. 213). Ambos terminam por reduzir o valor das coisas próprias deste mundo em nome de uma expectativa numa existência futura. Contudo, em termos práticos, se o cristianismo adota uma ascese que seria uma vingança que se volta contra si mesmo, a ascese no budismo não apresentaria um caráter moral, mas contornos de uma higiene do espírito, realizada com propósitos fisiológicos: "primeiro passo para a convalescença". Um refinamento da análise que se torna possível na medida em que Nietzsche passa a utilizar o conceito de ressentimento como um parâmetro, no caso, para avaliar as peculiaridades da saída sacerdotal para niilismo suicida.

Neste ponto, contudo, o conceito de ressentimento utilizado por Nietzsche, por mais que derive do diálogo com Dühring, que mencionei anteriormente, já não corresponde mais àquela ideia de uma reação mecânica que se tem nos escritos do Professor de Berlim. O que obriga Nietzsche a pontuar as diferenças do conceito que ele está empregando em relação ao seu antecessor. Isso tem lugar

\footnotetext{
${ }^{5} \mathrm{Na}$ seção 96 de Aurora tem-se um desenvolvimento desse tema, que consiste numa religião que não teria necessidade de uma divindade. Conferir também, em relação ao cristianismo, AC 65.
} 
na seção 15 da terceira dissertação da Genealogia, onde o filósofo retoma de forma crítica a ideia de ressentimento de Dühring, lembrando que ela corresponde a uma reação reflexa e mecânica frente a uma agressão (DÜHRING, 1875, p. 224) e deixando claro que, para ele, Nietzsche, o ressentimento não seria um "contragolpe defensivo" ou a um "movimento reflexo' em resposta a uma súbita lesão ou ameaça". Para Nietzsche, é unicamente no "desejo de entorpecimento da dor através do afeto" que se encontraria a "a verdadeira causação fisiológica do ressentimento" (GM III 15). O que sintetiza, segundo Marco Brusotti (1992, p. 82), a mudança de paradigma de Nietzsche em relação a Dühring. O que, também, permite entender o acento especial conferido, por Nietzsche, à ideia de "espírito da vingança", de "sede de vingança" (GM I 7), de "ânsia [desejo] de vingança" (GM I 8) e, ainda, à ideia de "vingança in effigie" (GM I 10). Permite observar também o modo como ele afasta desses termos a ideia da vingança de fato, em ato, a reação imediata, para fora, que seria própria do nobre (GM I 10) e não do fraco.

Na Genealogia, ainda, o conceito de ressentimento é utilizado por Nietzsche também em sua crítica aos filósofos que trabalham em prol da moral e, entre eles, o próprio Eugen Dühring, que é designado por ele como o "apóstolo da vingança" (GM III 14). Uma expressão que Nietzsche utiliza preferencialmente para Paulo (AC 45), o apóstolo, e que ao associar a Dühring, permite designá-lo igualmente como um enviado, um embaixador, um representante cuja tarefa seria de ampliar as fronteiras da moral do ressentimento. Numa analogia, se Paulo expandiu o ressentimento para fora das fronteiras do judaísmo, Dühring realiza a tarefa de expandi-lo para fora das fronteiras da moral cristã. O que ele faz por meio do deslocamento para o campo da justiça daquele mesmo princípio, o da vingança, que se encontraria na base da religião e da moral cristã (GM I 14) e que ele coloca no centro de sua tese, segundo a qual "o sentimento de justiça é essencialmente um ressentimento, um sentimento reativo, isto é, que pertence ao mesmo gênero que a vingança" (DÜHRING, 1865, p. 219). Uma tese que traz embutida também a ideia cristã de redenção, pois a aplicação da justiça restauraria, por meio de uma "negação da negação" (DÜHRING, 1865, p. 97), o próprio direito, que teria sido atingido pelo delito, numa espécie de Aufhebung ao modo hegeliano. ${ }^{6}$ O que corresponderia, ainda, a um desígnio da própria natureza, uma vez que também o homem estaria submetido àquela lei da física, segundo a qual, um corpo que sofre uma ação tende naturalmente a produzir uma reação no sentido oposto. (DÜHRING, 1865, p. 4 e 1875, p. 226). Desse modo, Dühring estaria secularizando os princípios religiosos e expandindo os pressupostos da moral cristã para outros campos, no caso, para o campo da justiça, fundamentando-os na filosofia e na ciência de sua época.

\section{O NADA COMO SAÍDA PARA O HORROR AO NADA}

Quanto a Schopenhauer, sua importância para a dissertação é bem maior do que a de Dühring. O filósofo de Frankfurt é, ao certo, de acordo com Marco

\footnotetext{
${ }^{6}$ Na Filosofia do Direito de Hegel essa questão, que é central, encontra-se, por exemplo, nos parágrafos 99 e 225.
} 
Brusotti, (2001, p. 117), o principal interlocutor e adversário de Nietzsche na terceira dissertação da Genealogia. Ele aparece inicialmente no texto quando Nietzsche se pergunta pelo significado do ideal ascético para os filósofos, nas seções 6 a 8. Porém, seu principal papel se dá justamente no modo como Nietzsche desdobra o tema da negação da vontade a partir do desfecho do livro $O$ mundo como vontade e representação, tomando seu mestre como como ponto de partida, ao início da dissertação, e invertendo-o no desdobramento do texto e em especial na sua parte final.

Como é amplamente conhecido, para Schopenhauer, a vontade traz consigo "sofrimento incurável e tormento" (MVR 71) para o homem. Um tormento que pode ser solucionado, segundo ele, por meio de uma quietação da vontade, que pode se desdobrar numa supressão da vontade. O que Nietzsche associa, conforme vimos anteriormente, no texto da Genealogia, ao sacerdote ascético, que teria como objetivo "a própria redenção, aquela hipnotização e quietude total enfim alcançada" (GM III 17).

Ao referir-se a uma "quietação da vontade" (Quietiv des Willens), Schopenhauer coloca em foco uma peculiaridade da vontade que denomina "vontade de vida", que seria a forma mais veemente da vontade e, por conseguinte, aquela na qual o conflito se manifesta de maneira mais visível e o sofrimento é mais intenso. Por esse motivo ele se volta especialmente para essa forma da vontade quando se refere à "negação" da vontade, apontando como meios para isso a "ascese" e a "mortificação da vontade própria". Meios que permitiriam ao homem atingir um "quietismo de todo querer" (MVR 68).

No quarto livro d'O mundo... intitulado "Metafísica da ética", em que Schopenhauer coloca em evidência a "afirmação ou negação" da vontade, ele aponta o asceta como uma das figuras que melhor traduz o desejo de aquietar a vontade por meio de uma renúncia de si, de uma renúncia da vida e do egoísmo (MVR 66). Do mesmo modo como também aponta o cristianismo e as religiões orientais como caminhos para essa saída do sofrimento.

Essa questão da negação da vontade, extremamente complexa em Schopenhauer, tem seu desfecho na seção 71 do livro IV d'O Mundo.... Nessa seção, considerando o caráter paradoxal da vontade, ele afirma que é somente porque "queremos a vida, e nada somos senão essa vontade e nada conhecemos senão ela" (MVR 71), que aquilo que o asceta encontra é para nós "apenas o nada" e alvo de nossa repugnância. Desse modo, a superação da vontade não teria sentido para os homens marcados pela "indigência e aprisionamento", mas somente para aqueles que "ultrapassam o mundo". Para esses últimos, segundo Schopenhauer, "a vontade, tendo alcançado o pleno conhecimento de si, encontrou-se novamente em todas as coisas e em seguida se negou livremente". Neles, ao invés do desejo e esperança por satisfação, encontrar-se-ia "a paz superior a toda razão, aquela calmaria oceânica do espírito, aquela profunda tranquilidade, confiança inabalável e serenidade jovial". Nas palavras do filósofo, em tais homens "apenas o conhecimento restou, a Vontade desapareceu" (MVR 71). 
Tal ideia de negação da vontade, que poderia ser identificada ainda na experiência dos santos cristãos e também naquilo que fora chamado de uma "reabsorção no Brahma, ou Nirvana dos budistas" (MVR 71), é "confessada" pelo filósofo, ao fim do livro, porém, nesse momento, sem utilizar a terminologia religiosa. Em termos próprios, portanto, ele afirma: "o que permanece após a total superação da vontade, para todos aqueles que ainda estão cheios de vontade, é certamente o nada. Porém, inversamente, para aqueles nos quais a vontade se retirou e foi negada, para eles esse nosso mundo de tal forma real com todos os seus sóis e galáxias é - Nada" (MVR 71).

Se, nesses termos, em sua "confissão" final, Schopenhauer se coloca para além do âmbito da religião, na interpretação de Nietzsche o ateísmo de Schopenhauer não o afastaria do ideal ascético, visto que sua superação da vontade seria da mesma ordem daquela que se exprime por meio do conceito de ideal ascético. Por seu turno, o ateísmo de Nietzsche compreende uma crítica àquele ideal religioso de um além que compromete o valor da existência hodierna. O que ele faz mostrando que aquela ideia de uma "total superação da vontade" não corresponderia, de fato, a uma redenção enfim alcançada, mas a uma hipnotização, a um "entorpecimento da dor através do afeto" (GM III 15). Uma ideia que ele traduz por meio de termos como "hipnotismo", "hibernação", "estivação", etc., que aparecem várias vezes na dissertação e que são extraídos, em grande parte, do livro de James Braid, O hipnotismo. ${ }^{7}$ Assim, mais apegado do que Schopenhauer aos sóis e às galáxias, Nietzsche buscará fundamentar sua tese sobre a negação da vontade não no campo do misticismo ou numa filosofia metafísica, que não se diferencia do misticismo, mas no da ciência. Para isso, ele irá considerar as possibilidades abertas pelo médico inglês de se obter no homem o mesmo efeito verificado nos animais nas plantas: um estado correlato ao da hibernação, um sono profundo, no qual as condições vitais seriam igualmente reduzidas, ficando o corpo num "estado hipnótico" (BRAID, 1882, p. 72).

Portanto, se Nietzsche concorda com Schopenhauer, que as religiões orientais atuam sobre a vontade, em especial sobre a vontade de vida, e se ele abre a terceira dissertação da Genealogia ligando-a diretamente com a seção final d'O Mundo como vontade e representação, e com a tese de que o horror da vontade humana seria "o nada" (CONSTÂNCIO, 2018, p. 63), o fato é que, para ele, o que as religiões produzem é, em última instância, aquele estado hipnótico e de entorpecimento. O que corresponde, também para ele, em termos fisiológicos e não religiosos, a "uma tentativa de alcançar para o homem algo aproximado ao que a hibernação representa para algumas espécies animais, (..), um mínimo de metabolismo, no qual a vida ainda existe, sem, no entanto, penetrar na consciência" (GM III 17). Como num estado letárgico, portanto, a própria vida passaria a assemelhar-se a um longo e profundo sono, com a eliminação de todo desejo, de todo ato. O ápice desse estado, a meta final daquele empreendimento

\footnotetext{
${ }^{7}$ Apresento de forma mais detalhada o uso de James Braid por Nietzsche em "Artes de hipnose e de entorpecimento na terceira dissertação de Para a Genealogia da moral', publicado em 2008 na coletânea intitulada 120 anos de Para a genealogia da moral.
} 
sobre a vontade, seria "a própria redenção, aquela hipnotização e quietude total enfim alcançada” (GM III, 17). O nada desejado e enfim alcançado.

Neste ponto, outra referência central para Nietzsche, também da ciência de sua época, é a obra de Leon Dumont, Prazer e dor: teoria científica da sensibilidade. ${ }^{8}$ Em seu exemplar do livro de Dumont, Nietzsche sublinha as passagens nas quais Dumont crítica os fisiólogos de seu tempo, afirmando que eles consideravam a dor apenas como um sintoma e buscavam controlá-la por meio de anestésicos. Conforme vimos em outra ocasião, "segundo Dumont, tal procedimento não combate as causas do sofrimento, ao contrário, limita-se apenas a reduzir a dor a um estado elementar, a ponto de não se ter mais conhecimento dela". ${ }^{9}$ O que corresponde à crítica de Nietzsche à intervenção feita pelo sacerdote ascético, por meio da qual "apenas o sofrimento mesmo, o desprazer do sofredor, é combatido e não a sua causa, não a doença propriamente". (GM III, 17) A doença segue seu curso aprofundando-se em um homem que, graças aos próprios médicos, torna-se ainda mais debilitado e dependente de estimulantes e "aguardentes" (GM III 26), em especial de "aguardentes do espírito", o que faz a filosofia, por exemplo, ao secularizar o ideal ascético.

\section{CONSIDERAÇÕES FINAIS}

Em síntese, mantendo no horizonte apenas o modo como o conceito de niilismo aparece na terceira dissertação da Genealogia, ${ }^{10}$ pode-se dizer que ele designa, por um lado, aquele "vacui" em relação ao qual o homem tem horror. O que Nietzsche chama também de "niilismo suicida" e que corresponde ao problema capital do homem, que não é o sofrimento, mas o de estabelecer um sentido para o sofrimento. Por outro lado, o termo niilismo designa também o nada enquanto uma resposta possível àquele problema. Trata-se da resposta ao sentido da existência que é dado pelas religiões em geral. Uma resposta que é chancelada por Schopenhauer como um quietismo da vontade e que Nietzsche entende, como um estado letárgico, com base na ciência de sua época.

Neste ponto, tendo em vista essa ideia de nada, temos um primeiro ponto daquela reviravolta realizada por Nietzsche em relação a Schopenhauer. Para Nietzsche, inversamente de Schopenhauer, o "nada" não é este mundo dos sóis e galáxias (MVR 71), mas aquele imaginado pelas religiões, visto tratar-se, em última instância, de nada mais do que um sintoma de um adoecimento da vontade.

\footnotetext{
${ }^{8}$ O título disponível na biblioteca de Nietzsche - Vergnügen und Schmerz: zur Lehre von den Gefühlen. Leipzig: Brockhaus, 1876 - é uma tradução do original francês: Théorie Scientifique de la Sensibilité. Le Plaisir et la Peine. Paris: Germer Baillière, 1875.

${ }^{9}$ PASCHOAL, 2008, p. 53. Cf.: Leon Dumont, 1876, p. 138.

${ }^{10} \mathrm{O}$ niilismo é um dos temas mais controversos e mais estudados na filosofia de Nietzsche. As interpretações sobre ele vão desde os trabalhos de Heidegger, passando pelo clássico livro de Elisabeth Kuhn (Friedrich Nietzsches Philosophie des europäischen Nihilismus. Berlin /New York: De Gruyter, 1992), até trabalhos mais recentes, dentre os quais se pode citar o de Eike Brock (Nietzsche und der Nihilismus. Berlin / New York: De Gruyter, 2015) e, no Brasil, as publicações de Clademir Araldi sobre o tema (Niilismo, Criação, Aniquilamento: Nietzsche e a Filosofia dos Extremos. Ijuí: Ed. UNIJUÍ, 2004). Trabalhos que indicamos como primeiras sugestões para quem tem interesse em avaliar o alcance do tema e suas variações no conjunto da filosofia de Nietzsche.
} 
Por sua vez, o conceito de "ressentimento", considerado também apenas ao modo como aparece na terceira dissertação da Genealogia, ${ }^{11}$ ele não é tomado tanto pelo seu significado, mas pelos diferentes papéis que desempenha no texto. Nesse sentido, ele é um signo para designar o tipo de homem o fraco, marcado em especial por seu adoecimento e que cresce no solo do autodesprezo, onde "pululam os vermes da vingança e do rancor" (GM III14). Um tipo de homem que necessita de estimulantes para não se autodestruir, e que, por isso mesmo, é facilmente seduzido pelo ideal ascético. Ele é um signo também para o sacerdote ascético, que é caracterizado por seu "ressentimento impar, aquele de um insaciado instinto e vontade de poder que deseja assenhorear-se" (GM III 11). Por fim, o termo "ressentimento" designa o papel exercido por certos filósofos que seriam "apóstolos" da vingança, como é o caso de Dühring, que ampliam os horizontes do alcance da moral do ressentimento.

Quanto ao vínculo entre o niilismo e o ressentimento na dissertação, ele se encontra no desafio que é para o homem a questão do sentido da existência e do sofrimento inerente a ela. Um desafio que se aprofunda quando se tem no horizonte aquele homem fraco, doente, e a sua propensão para estados hipnóticos. Tem-se, assim, um vínculo entre o niilismo e o ressentimento no modo como o ressentimento demanda ideais e, ao mesmo tempo, favorece a produção daquele excesso de sentimento que é indispensável ao ideal ascético. No modo como, no Ocidente, o conhecimento de si se vinculou ao ideal ascético, num autoconhecimento que se volta contra si mesmo - por vingança ou por compaixão.

Neste ponto, um intérprete mais afoito poderia rapidamente associar a Schopenhauer a ideia de apóstolo da moral do ressentimento, como Nietzsche associa a Dühring. Contudo, o fato é que Schopenhauer tem um papel bem diferente no texto de Nietzsche. Conforme vimos, o Filósofo de Weimar reconhece sua importância de Schopenhauer para o debate sobre o tema do sofrimento, tanto que, conforme apontamos, vincula o texto da dissertação diretamente à parte final de $O$ mundo como vontade e representação de Schopenhauer. Ao certo, contudo, esse reconhecimento não deixa de ser crítico, em primeiro lugar porque, em primeiro lugar, a solução para o sofrimento pensada por Schopenhauer reitera o discurso religioso e moral; em segundo lugar, porque ele, assim, desconsidera o caráter fisiológico desse sofrimento, como algo inerente à existência e, por fim; em terceiro lugar, coloca em foco o sofrimento e não o que é para Nietzsche o principal problema que não é o sofrimento, mas o do sentido para o sofrimento.

Contudo, justamente neste ponto, ao pensar a solução do sofrimento por meio da supressão da vontade, ele confere ao problema pensado por Nietzsche, o do sentido, um sentido. Tal resposta ao problema, que reitera o sentido conferido ao sofrimento pelas grandes religiões, foi, ao certo, na perspectiva de Nietzsche. Contudo, ela foi um "faute de mieux" (GM III 28). Pois, como ela "continua sendo uma vontade" (GM III 28), um sentido, ela impediu aquela total falta de sentido, o niilismo suicida e, assim, manteve aberta a possibilidade de novos sentidos para a

${ }^{11}$ No livro Nietzsche e o ressentimento (São Paulo: Humanitas, 2014) apresento as variações do uso do termo por Nietzsche bem como a sua ligação com Dühring e também com Dostoiévski. No livro aponto ainda uma vasta referência de estudos sobre o tema. 
existência, a partir de novas perspectivas, talvez a do budismo ou, no seu limite, a dos "comediantes do ideal ascético" (GM III 26).

\section{REFERÊNCIAS}

ARALDI, Clademir. Niilismo, Criação, Aniquilamento: Nietzsche e a Filosofia dos Extremos. Ijuí: Ed. UNIJUÍ, 2004

BRAID, James. Der Hypnotismus. Berlin: Verlag von Gebruder Paetel, 1882.

BROCK, Eike. Nietzsche und der Nihilismus. Berlin / New York: De Gruyter, 2015. BRUSOTTI, Marco. Die "Selbstverkleinerung des Menschen" in der Moderne: Studie zu Nietzsches "Zur Genealogie der Moral”. In: Nietzsche-Studien 21: 81-136, 1992.

. "Wille zum Nichts, Ressentiment, Hypnose. 'Aktiv' und 'Reaktive' in

Nietzsches Genealogie der Moral”. In: Nietzsche-Studien 30: 107-132, 2001.

CONSTÂNCIO, João. Schopenhauer mestre de Nietzsche: sobre niilismo e ascetismo. Revista Sofia, v. 7, n. 02, p. 59-81, jul./Dez. 2018.

DÜHRING, Eugen. Der Werth des Lebens. Breslau: E. Trewendt, 1865.

Cursus der Philosophie als streng wissenschaftlicher Weltanschauung und Lebensgestaltung. Leipzig: Erich Koschny, 1875.

DUMONT, Léon. Vergnügen und Schmerz. Zur Lehre von den Gefühlen. Leipzig: F. A. Brockhaus, 1876.

HEGEL, G. W. Friedrich. Grundlinien der Philosophie des Rechts. 2. ed. Vol. 7 da Werke: [in 20 Bänden]. Frankfurt am Main: Suhrkamp, 1989.

KUHN, Elisabeth. Friedrich Nietzsches Philosophie des europäischen Nihilismus. Berlin / New York: DeGruyter, 1992.

NIETZSCHE, Friedrich. Morgenröthe. Idyllen aus Messina. Die Fröhliche Wissenschaft. Kritische Studienausgabe (KSA) Herausgegeben von Giorgio Colli und Mazzino Montinari. Bd. 03. München/Berlin/New York: dtv/Walter de Gruyter, 1988.

- Jenseits von Gut und Bose. Zur genealogie der moral. Kritische Studienausgabe (KSA) Herausgegeben von Giorgio Colli und Mazzino Montinari. Bd. 05. München/Berlin/New York: dtv/Walter de Gruyter, 1988.

Der Fall Wagner. Götzen-Dämerung. Der Antichrist. Ecce homo. DionysosDithyramben. Nietzsche contra Wagner. Kritische Studienausgabe (KSA) Herausgegeben von Giorgio Colli und Mazzino Montinari. Bd. 06. München/Berlin/New York: dtv/Walter de Gruyter, 1988.

Nachgelassene Fragmente 1875-1879. Kritische Studienausgabe (KSA) Herausgegeben von Giorgio Colli und Mazzino Montinari. Bd. 08. München/Berlin/New York: dtv/Walter de Gruyter, 1988. 
NIETZSCHE, Friedrich. Nachgelassene Fragmente 1885-1887. Kritische Studienausgabe (KSA) Herausgegeben von Giorgio Colli und Mazzino Montinari. Bd. 12. München/Berlin/New York: dtv/Walter de Gruyter, 1988.

. Genealogia da moral. Trad. Paulo César de Souza. São Paulo: Brasiliense, 1987.

. Ecce homo. Trad. Paulo César de Souza. São Paulo: Cia das letras, 1995.

PASCHOAL, A. E. \& FREZZATTI, W. A. (orgs.). 120 anos de "Para a genealogia da moral". Ijuí: Ed. UNIJUÍ, 2008.

Do niilismo às artes de higiene: o budismo nos escritos de Nietzsche. In: André Luiz Muniz Garcia e Lucas Angioni (orgs.). Labirintos da Filosofia: Festschrift aos 60 anos de Oswaldo Giacoia Jr. Campinas: Editora Phi, 2016, pp. 234-252.

SCHOPENHAUER. A. Die Welt als Wille und Vorstellung I. Zürich: Haffmans Verlag, 1988. 